\title{
Spermatic Pedicle Inflammation as the Initial Sign of Henoch-Schönlein Purpura
}

CLAUDE BACHMEYER, MD; ZIYAD BOURGOU, MD, Service de Médecine Interne; MIKHAEL BENJOAR, MD; BENJAMIN LANGMAN, MD, Service de Radiologie; ANGE HANOUNA, MD, Service de Médecine Interne, Hôpital Tenon (AP-HP); LOIC GUILLEVIN, MD, PhD, Service de Médecine Interne, Hôpital Cochin (AP-HP), Paris, France. Address correspondence to Dr. C. Bachmeyer, Service de Médecine Interne, CHU Tenon (AP-HP), 4 rue de la Chine, 75020 Paris, France. E-mail: claude.bachmeyer@tnn.aphp.fr. J Rheumatol 2012;39:2041-2; doi:10.3899/jrheum.120428

Involvement of urinary and genital structures in Henoch-Schönlein purpura (HSP) is fairly common in children, but unusual in adults. We present the case for including the spermatic pedicle among the structures that can be involved.

A 59-year-old man was referred for abdominal and right testicular pain lasting for 3 weeks, and arthralgia and purpura for 1 week. His temperature was $38.1^{\circ} \mathrm{C}$. Sensitive right lower abdominal quadrant, increased by palpation, palpable purpura on lower limbs (Figure 1), and knee and wrist arthralgia were present, but urological examination was normal. Laboratory tests showed hyperleukocytosis, elevated C-reactive protein, and normal serum creatinine, urinalysis and liver function tests. Investigations for antinuclear and antineutrophil cytoplasmic antibodies, rheumatoid factor, and cryoglobulinemia were negative, as well as tests for human immunodeficiency virus, hepatitis $\mathrm{B}$ and $\mathrm{C}$ virus, and blood cultures. Cutaneous biopsy of palpable purpura disclosed a small leukocytoclastic vasculitis with deposits of immunoglobulin A (IgA) in the blood vessel wall. Computed tomography (CT) scan demonstrated right spermatic pedicle thickening (Figure 2). Imaging using [18F]-2-fluoro-deoxy-D-glucose showed accumulation of the tracer limited to the right spermatic pedicle. Diagnosis of HSP was established, indicated by spermatic pedicle involvement. Treatment with prednisone $1 \mathrm{mg} / \mathrm{kg} /$ day progressively tapered over 6 months resulted in dramatic improvement of clinical signs and laboratory and CT scan abnormalities.

HSP is a small-vessel vasculitis characterized by $\operatorname{IgA}$ and C3 deposits in the vessel wall that cause palpable purpura, arthralgia or arthritis, abdominal pain, gastrointestinal bleeding, and renal disease, predominantly in children $^{1}$.

Involvement of urinary and genital structures is observed in $2 \%$ to $38 \%$ of patients in pediatric series ${ }^{1}$, but it is unusual in adults. Involvement of the scrotal wall, glans penis, epididymis, testis, spermatic cord, ureter, and bladder has been reported ${ }^{2,3,4}$. The spermatic pedicle should be added to this list.

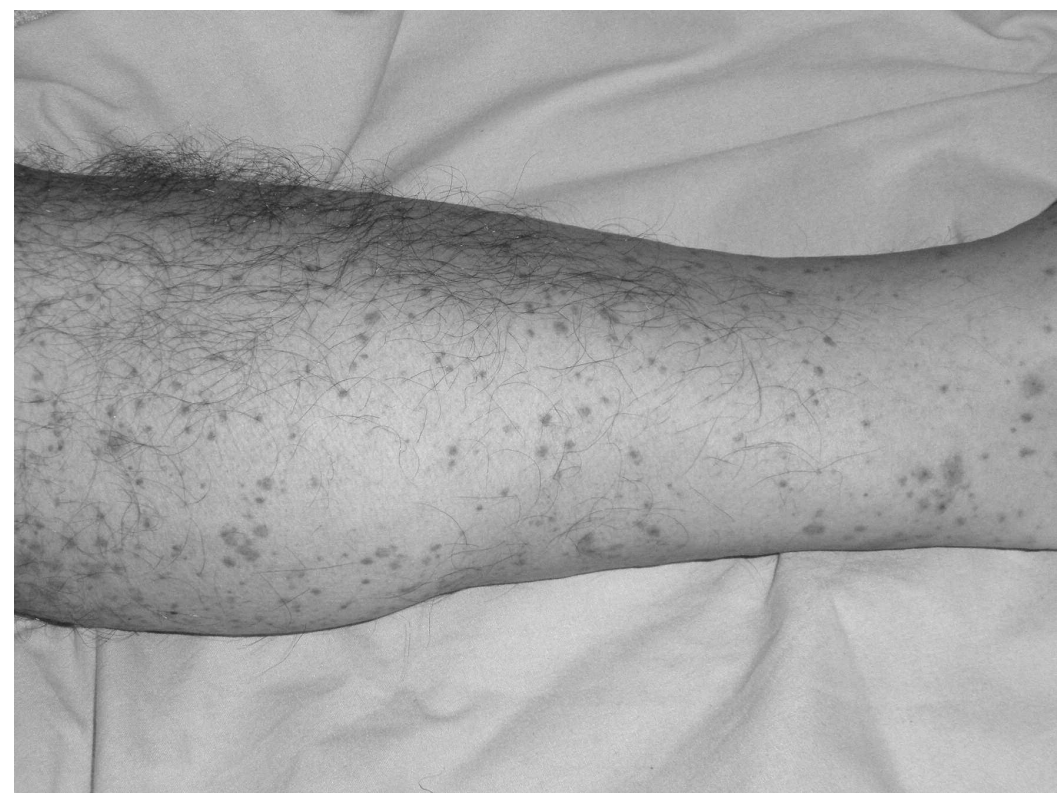

Figure 1. Palpable purpura of lower limbs. 


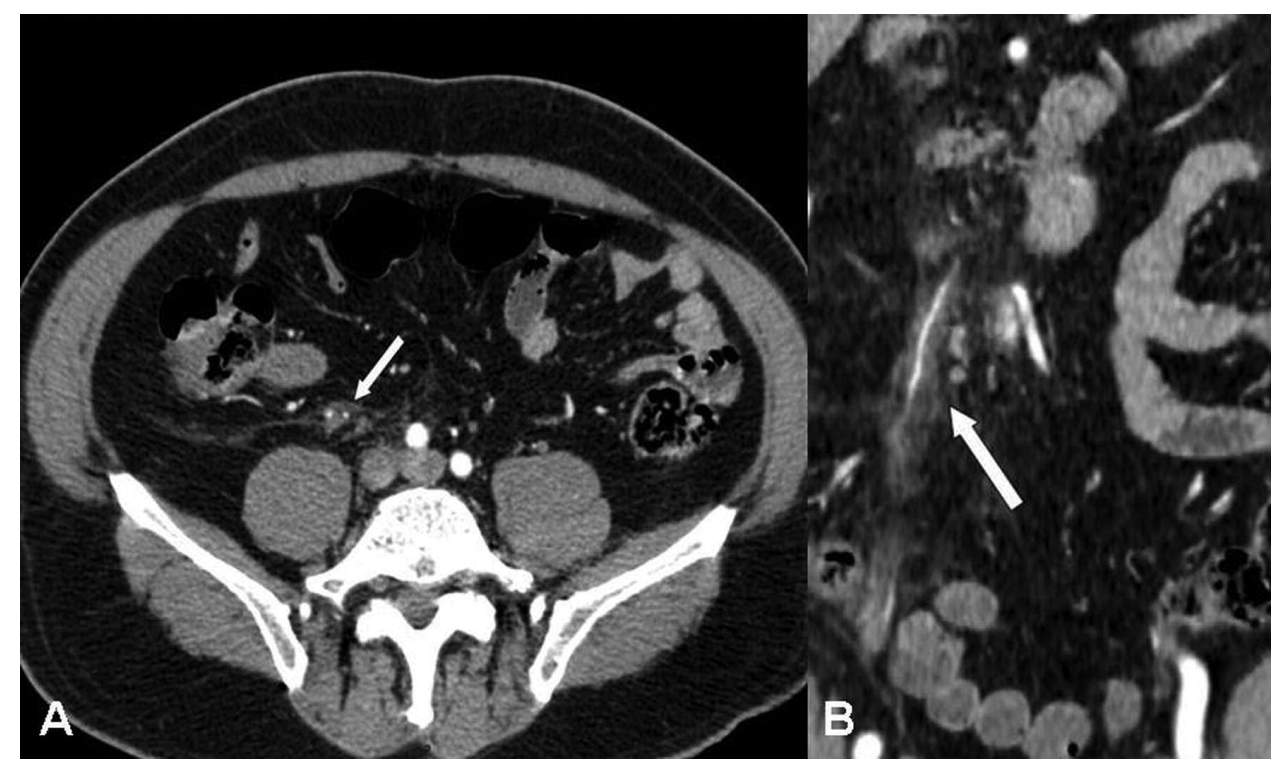

Figure 2. Abdominal computed tomography (CT) scan after intravenous administration of iodinated contrast agent. A. Axial CT scan showing right spermatic pedicle thickening but no vein thrombosis. B. Coronal CT scan showing the extension of the right spermatic pedicle thickening (arrow), and the absence of venous thrombosis.

\section{REFERENCES}

1. Saulsbury FT. Henoch-Schönlein purpura in children. Report of 100 patients and review of the literature. Medicine 1999;78:395-409.

2. Davol P, Mowad J, Mowad CM. Henoch-Schönlein purpura presenting with orchitis: A case report and review of the literature. Cutis 2006;77:89-92.
3. Sudakoff GS, Burke M, Rifkin MD. Ultrasonographic and color Doppler imaging of hemorrhagic epididymitis in Henoch-Schönlein purpura. J Ultrasound Med 1992;11:619-21.

4. Pfister C, Liard-Zmuda A, Dacher J, Dubois D, Grise P, Mitrofanoff $P$. Total bilateral ureteral replacement for stenosing ureteritis in Henoch-Schönlein purpura. Eur Urol 2000;38:96-9. 